\title{
24. AN AUTOMATED $P$-WAVE LOGGER FOR RECORDING FINE-SCALE COMPRESSIONAL WAVE VELOCITY STRUCTURES IN SEDIMENTS 1
}

\author{
P. J. Schultheiss ${ }^{2}$ and S. D. McPhail ${ }^{2}$
}

\begin{abstract}
An automated system for measuring the compressional wave velocity, $V_{p}$ ( $P$-wave velocity), of sediments has been developed. The $P$-wave logger (PWL) has been designed to measure accurately and to record automatically the $P$-wave velocity of soft sediments within a cylindrical plastic core liner. By recording the velocity profile of a sequence of adjacent core sections, a very detailed velocity log can be obtained.

Although the PWL was developed specifically for the Ocean Drilling Program to use on cores obtained with the hydraulic piston corer on board the drilling vessel JOIDES Resolution, it can easily be used on more conventional cores obtained by piston and gravity corers that use any type of cylindrical plastic liners.

Velocity measurements are automatically taken, with a relative precision of $1.5 \mathrm{~m} / \mathrm{s}$, at regular intervals along each core section as it travels between a pair of ultrasonic transducers. The PWL was designed to be incorporated into a new whole-core logging system that will also include gamma-ray attenuation and magnetic susceptibility. For evaluation purposes the PWL was first used on Leg 108 in conjunction with the old GRAPE system. Over $3 \mathrm{~km}$ of cores were logged without any major malfunctions, and many fine-scale velocity structures were revealed that would have gone unnoticed previously.
\end{abstract}

\section{INTRODUCTION}

Throughout the history of ocean drilling (since Deep-Sea Drilling Project Leg 15), ultrasonic compressional wave velocities have been measured, at a frequency of $400 \mathrm{kHz}$, using a velocimeter known as the Hamilton Frame. Boyce (1973, 1976) described this equipment and the techniques for its calibration and use. Although this apparatus has performed an admirable service to physical property scientists on many ocean drilling legs, it has the inherent disadvantage of being very time consuming and operator dependent. Each single velocity measurement had to be performed manually on either a chunk sample or through the split liner. In addition, the operator had to choose the interval within each section for measurement.

In practice this has meant that when cores were taken in soft sediments with the hydraulic piston corer (HPC), velocities have been taken on average only about once per section (i.e., every $1.5 \mathrm{~m}$ ) at the most. Even though one can obtain the overall average velocity gradient at this sampling interval, one cannot resolve fine-scale detail on a routine basis. This type of detail could only be obtained in special circumstances and with considerable effort. Also, it was possible to miss many velocity peaks and troughs altogether either because of their sheer numbers or because their presence is often not revealed by a visual inspection of the split cores.

With the $P$-wave logger (PWL), we hope that fine-scale velocity profiles will (1) enable participating scientists to make accurate correlations of adjacent HPC holes, (2) provide high-quality data for synthetic seismograms and help the interpretation of seismic records, and (3) indicate the nature of sedimentary features not easily detected by conventional means.

At deeper sites where core quality is poorer, the Hamilton Frame will still be used for measuring the velocity of discrete

\footnotetext{
${ }^{1}$ Ruddiman, W., Sarnthein, M., et al., 1989. Proc. ODP, Sci. Results, 108: College Station, TX (Ocean Drilling Program).

2 Institute of Oceanographic Sciences, Brook Road, Wormley, Godalming, Surrey GU8-5UB, United Kingdom.
}

samples. However, PWL electronics can be used with the Hamilton Frame and will considerably improve the ease, reliability, and accuracy of its operation.

The purpose of this paper is to introduce the basic principles and operation of the PWL and to illustrate, with two example records from Leg 108, the type of data that can be obtained. Although significant changes to the tracking mechanism and to the computer handling of the data will be made in the future, the underlying principles outlined in this paper will remain the same, and it should prove of value to anyone using the instrument or interpreting data obtained from it.

\section{PRINCIPLES OF OPERATION}

The PWL measures the speed of ultrasonic compressional waves in sediments by timing pulses traversing across the diameter of a sediment-filled whole-core liner. An "ear-muff" pair of spring-loaded transducers (transmitter and receiver) are located diametrically across the core, which travels along its axis between the stationary transducers. During logging it is essential to maintain a good ultrasonic coupling between the compressional wave transducers and the core liner; this is achieved by spraying the outside of the liner with water.

The mechanical arrangement of the transducers around the core is shown schematically as part of the overall PWL diagram in Figure 1. It is possible to arrange for the transducers to move along a stationary core. This alternative arrangement has an advantage in that it occupies only half the bench space that the Ocean Drilling Program (ODP) system described here uses.

The PWL can be used on a routine basis to obtain detailed velocity profiles throughout the length of high-quality cores. The sampling interval down the length of the core can be chosen by the operator and can be as small as $1 \mathrm{~mm}$ (although for reasons discussed later a practical sampling interval is about $2 \mathrm{~cm}$ ). The data is fed directly to a computer, via an interface, for processing, real-time display, and storage. The large amount of data that can be obtained using this system requires the availability of a good software package. The package was originally developed for an Acorn $\mathrm{BBC}$ microcomputer, but it was only intended as a tempo- 


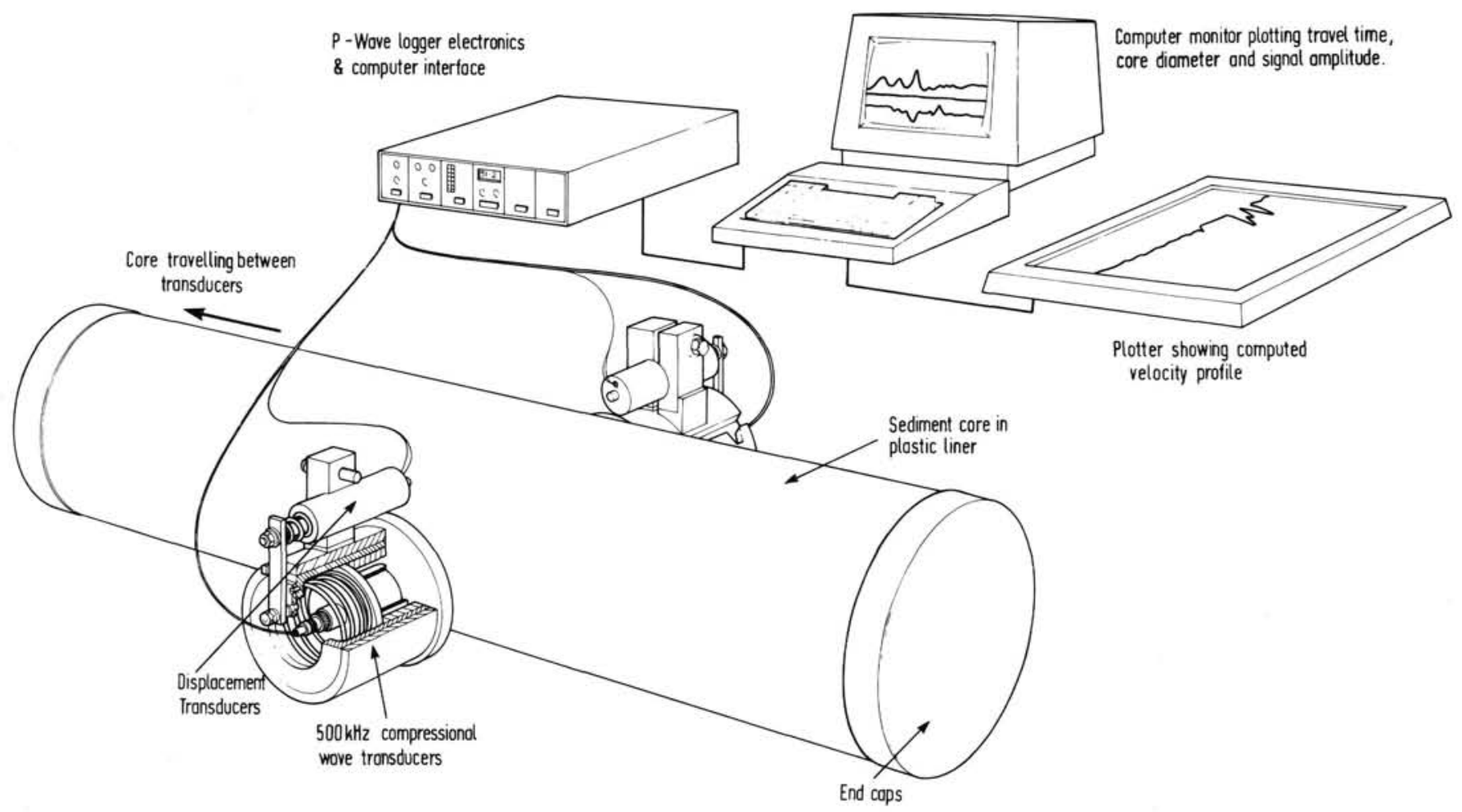

Figure 1. Schematic diagram of the $P$-wave logger.

rary measure and it has now been integrated into the ship-based computer system.

After suitable calibration procedures have been followed, the ultrasonic compressional wave speed of the sediment is calculated by the computer. These measurements are taken continuously while the core travels along its length through the transducer assembly.

\section{Ultrasonic Compressional Wave Transducers}

The mechanical construction of both the transmitter and the receiver are identical. A $500-\mathrm{kHz}$ PZT4, ceramic, piezoelectric compressional mode disc is circumferentially mounted and potted within an aluminum housing. The front face is a $1 / 4$-wavelength epoxy resin window that maximizes

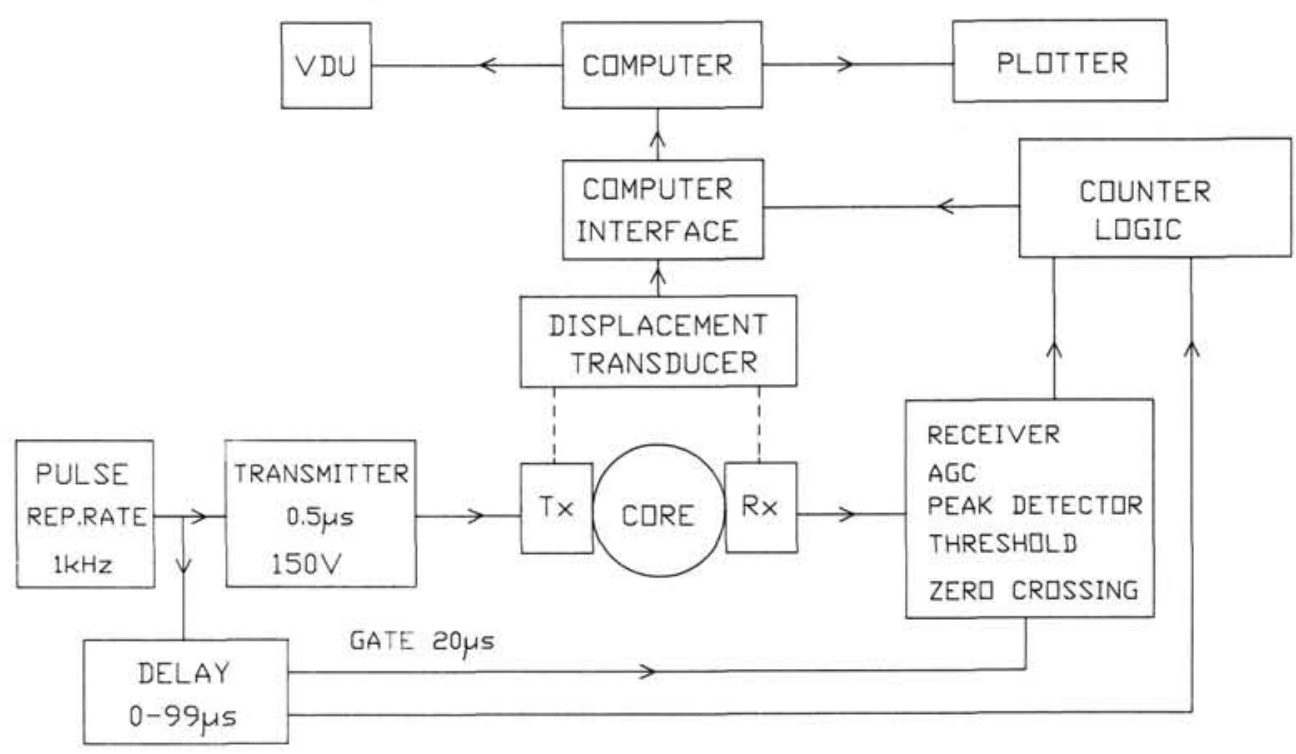

Figure 2. System block diagram of the complete $P$-wave logger. 


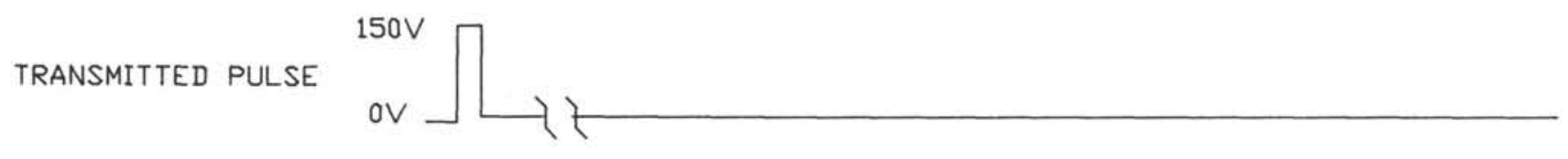

IV

RECEIVED SIGNAL (AFTER AGC)
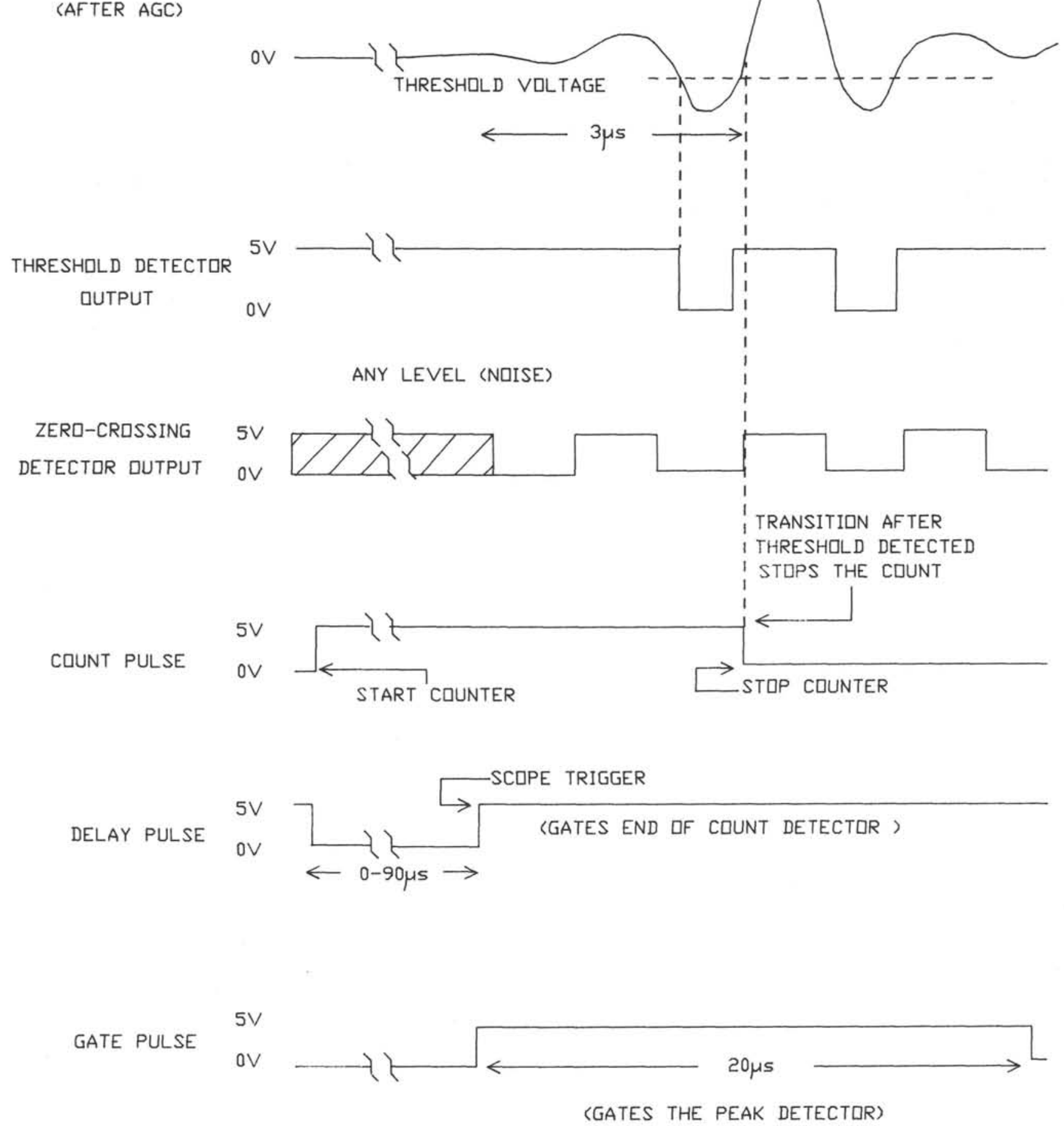

Figure 3. Pulse transmission and detection timing diagram for the $P$-wave logger. 
the forward energy transmission. The backing is a mixture of epoxy resin and "fly-ash" that attenuates and scatters the back transmission. Firm contact between the transducer face and the liner is maintained by springs located behind each transducer, which move like pistons in the barrel housing.

The receiver (RX) is wired to a two-pin connector with an overall screen to reduce electrical noise pickup, whereas the transmitter (TX) uses a single-screened wire and a BNC connector. The impedance at resonance is $100 \Omega$, which is suitable for direct connection to the transmitter and receiver circuits. The front faces of both transducer housings are chamfered to enable them to ride easily over the liner endcaps.

\section{Displacement Transducers}

Variations in the liner diameter will cause variations in the pulse traveltime. It is essential, therefore, to log the liner diameter at the same time as the pulse traveltime to obtain accurate velocity measurements. To accomplish this a pair of displacement transducers are mounted on the transducer block and coupled to the ultrasonic transducers. The displacement transducers are linear $1-\mathrm{K} \Omega$ potentiometers with 12.5 $\mathrm{mm}$ of travel and a $0.04-\mathrm{mm}$ bit resolution. They are connected in series such that the difference in their outputs is proportional to the distance between the ultrasonic transducer faces. The output is digitized and presented to the data bus. The transducer positions can easily be adjusted by the set screws to set them in the correct range.

\section{Pulse Transmission and Detection}

A system block diagram for the PWL is shown in Figure 2. The transmitter is excited by a short pulse ( $150 \mathrm{v}$ for $0.5 \mu \mathrm{s})$, which produces a short $500-\mathrm{kHz}$ compressional wave pulse that propagates throughout the core and is detected by the receiver. The performance of the system depends primarily on the accurate measurement of the traveltime of this ultrasonic pulse across the core. A counter (clocked at $20 \mathrm{MHz}$ ) is started as the transmitter is excited. On detection of the received pulse envelope, the counter is stopped. This operation is repeated at a rate of $1 \mathrm{kHz}$.

The detection of the instant of arrival of the received pulse is complicated by the need for (1) noise rejection, (2) good performance over a wide dynamic range, and (3) a time resolution of $50 \mathrm{~ns}$. Forcing the system to begin looking for a signal only after a set time delay following the transmission pulse enables the PWL to reject noise. This is the function of the delay user control, which can be set between 0 and $99 \mu \mathrm{s}$ using a thumbwheel switch. In addition to gating the detection circuits, the delay pulse is available as an output for scope triggering when monitoring the signal. During routine operations the delay will be set and will rarely need changing.

The dynamic range of the received signal can be high ( 80 dB) due to variations in the sediment attenuation and variable transducer-liner and sediment-liner contacts, which requires the use of an automatic gain control (AGC) amplifier. A peak detector is used to control the AGC amplifier gain. The peak detector operates on the received signal during a $20-\mu$ s gated period that occurs after the end of the delay period. This eliminates the feed-through of the transmitted pulse and any other noise spikes that may be present outside the $20-\mu \mathrm{s}$ window (see Fig. 3).

The required timing resolution ( $50 \mathrm{~ns}$ ) cannot be achieved by simply detecting the envelope of the received pulse train as the mechanical Q of the transducers is too high and hence the pulse length is relatively long. Figure 3 , which shows the relative timing of the pulse waveforms, illustrates how the accurate ultrasonic pulse detection is achieved. It relies on the detection of an identifiable zero crossing in the pulse. The output of the peak detector is used to set a threshold above which the signal is detected.

In the example shown in Figure 3, the second negative excursion of the pulse is detected. This threshold detection, however, is not of sufficient timing accuracy, given the possible variation in signal amplitude after the AGC amplifier. Therefore, the first zero crossing detected, after the threshold is exceeded, is used to stop the counter. This method makes the detection of the instant of signal arrival insensitive to amplitude jitter and to noise, as the slew rate is at a maximum at zero crossing. The time between the onset of the received pulse and the third zero crossing ( $3 \mu \mathrm{s})$ is used as a constant for the velocity calculation.

Logic circuits convert the outputs of the threshold detector and the zero crossing detector to the single count output. The count output is used to gate a counter module (10 MHz-clock) with an LCD output, giving the user a display of traveltime in $\mu \mathrm{s}(0.1-\mu \mathrm{s}$ resolution). The count output is also used to gate a separate counter clocked at $20 \mathrm{MHz}$, which outputs onto a data bus interfaced with the computer system. The timing resolution for this counter is $50 \mathrm{~ns}$.

A separate analog-to-digital converter (ADC) digitizes the output of the peak detector as an uncalibrated, relative measure of signal strength. This is, of course, nonlinear with respect to the input signal as the input to the peak detector is after the AGC amplifier. The speed of the ADCs limits the sampling rate to $\sim 500 \mathrm{~Hz}$.

\section{VELOCITY CALCULATIONS}

The velocity, $V$, of the ultrasonic $P$-wave pulse in the sediment, assuming that the liner is full of sediment, is given by

$$
V=D / T
$$

where $D$ is the diameter of the sediment core (inside diameter of the liner) and $T$ is the traveltime of the pulse through the sediment.

$$
D=D_{1}-2 d \text { and } T=T_{T}-T_{e}-T_{p}-2 t,
$$

where

$D_{1}=$ outside diameter of the liner,

$d=$ liner wall thickness,

$T_{T}=$ total traveltime recorded by the PWL,

$T_{e}=$ electronic and transducer delay time (obtained when transducer faces are held together),

$T_{p}=$ pulse time correction (difference between onset of pulse and the zero crossing detected by the PWL), and

$t=$ pulse traveltime through liner wall.

The outside diameter of the liner is monitored by the displacement transducers, such that

$$
D_{1}=D_{c}+\left(R_{c}-r\right) \mathrm{CAL},
$$

where

$D_{c}=$ the diameter of a calibration section,

$R_{c}=$ reading (bits) obtained with the calibration section in place,

$r=$ reading (bits), and

$\mathrm{CAL}=$ calibration of displacement transducers $(\mathrm{mm} / \mathrm{bit})$.

The following values were measured on Leg 108: $d=2.65$ $\mathrm{mm}, T_{e}=1.1 \mu \mathrm{s}, T_{p}=3.0 \mu \mathrm{s}$, and $\mathrm{CAL}=0.04 \mathrm{~mm} / \mathrm{bit}$. The velocity calculation is performed by software that also cor- 
rects the velocity to $20^{\circ} \mathrm{C}$ according to the following approximation:

$$
V_{20}=V_{T}+3(20-T),
$$

where $V_{20}=$ velocity at $20^{\circ} \mathrm{C}, V_{T}=$ velocity at $T^{\circ} \mathrm{C}(\mathrm{m} / \mathrm{s})$, and $T=$ temperature of core when logged $\left({ }^{\circ} \mathrm{C}\right)$.

The absolute resolution of the PWL is $50 \mathrm{~ns}$, which means that a velocity resolution of about $1.5 \mathrm{~m} / \mathrm{s}$ can be obtained in soft-sediment cores. However, the limiting factor is the tolerance (manufacturer's specification) of the liner wall thickness, which in practice limits the absolute accuracy to about $5 \mathrm{~m} / \mathrm{s}$. Nevertheless, the most useful function of the PWL is the relative velocity changes that occur; and these can be detected at an instrument resolution of $1.5 \mathrm{~m} / \mathrm{s}$.

\section{CALIBRATION}

The only procedure that is necessary to obtain the accurate velocity is to calibrate the displacement transducers. These transducers do not have a visual output and can only be "read" using the computer software. To ensure that the correct distance between the ultrasonic transducer faces is being used in the velocity calculation by the computer, a simple calibration procedure is followed.

The two displacement transducers measure the liner diameter such that when the transducer faces are moved synchronously from side to side the reading does not change.

To check the calibration, a core liner full of distilled water is placed on the carriage and the appropriate input parameters are entered into the computer. The velocity should be about $1500 \mathrm{~m} / \mathrm{s}$ (see on-board velocity standards table). For a complete description of the calibration procedures, the reader should refer to the manual.

\section{OPERATING PROCEDURE}

The ODP instruction manual contains a detailed account of the operating procedure. In routine use, after suitable calibrations have been performed, the operating procedure is simple. The core section is placed in its start position and sprayed with water. The operator then enters the core and section number identities at the keyboard and presses the start button. A hard-copy velocity profile is generated by the plotter, and a display of traveltime, signal amplitude, and core diameter is produced on the monitor in real time. A magnetic disc automatically stores data for future plotting, listing, or processing.

\section{EXPERIENCE AND ILLUSTRATIVE DATA FROM LEG 108}

On Leg 108 the PWL transducer assembly was mounted alongside the GRAPE source and detector and was used on most of the cores recovered. Over $3 \mathrm{~km}$ of cores were logged without any serious difficulties (Schultheiss and Meinert, 1988). We obtained $P$-wave logs from a range of sediment types: carbonate marls and oozes, siliceous oozes, clays, and silt and sand layers. Overall, the PWL system performed very well without any hardware breakdowns.

The GRAPE tracking system is archaic, slow, and at times unreliable. We understand that it has now been replaced by a more sophisticated core-tracking system that should eliminate many of the difficulties encountered on Leg 108. With the tracking system used on Leg 108, for example, it takes approximately $1.25 \mathrm{hr}$ to $\log$ a $9.5-\mathrm{m}$ core. On such a leg it was almost impossible to log everything because of the effect on the rate at which cores could be processed. The PWL data would not suffer in quality if the tracking speed could be increased by a factor of 5 . This would enable each core section to be logged in about 2 min.

\section{Transducer Coupling}

A good "acoustic" coupling is needed between the transducer and the liner and between the liner and the sediment if the compressional wave pulse is to propagate with sufficient amplitude to be timed accurately. Data loss from bad coupling can occur in several ways:

1. If the outside of the liner is dry. Each section must be sprayed with water.

2. If a transducer is stuck. The transducer acts like a spring-loaded piston and occasionally sticks in such a way that contact with the liner is lost.

3. If liners are split and damaged. In this case, the contact between the outside of the liner and the transducer (especially when tape is used) and/or the contact between the inside of the liner and the sediment can be affected.

4. Due to sediment type. The cutting shoe is about 4-mm smaller than the inside diameter of the liner; therefore, in some sediment types the cored material does not swell sufficiently to fill the liner completely. When cut into $1.5-\mathrm{m}$ sections, some water can drain out, which leaves a thin air gap that can strongly attenuate the signal. In sections with intermittent air pockets from the above cause, it is sometimes possible to decrease the number of "missed" readings by rotating the section during logging and maintaining the "best" signal on the oscilloscope. However, the system cannot be left unattended in this situation; thus, this is not a practical solution for frequent occurrences of this problem.

5. Due to the presence of gas. In sediments that contain even a small amount of free gas when the core reaches the deck, the signal is very strongly attenuated and useful logs are impossible to obtain. The inherent disadvantage of the PWL system is that it will only provide good quality data on high-quality cores that completely fill the liner. In practice, this means that only cores taken with the HPC in unlithified, nongassy sediments are really suitable although some reliable data can be obtained from XCB cores where sampling disturbance is minimal. Small amounts of gas inside the liner can completely attenuate the signal.

\section{Sampling Interval}

A series of tests using the PWL set at different sampling intervals have shown that there is little point in having a sampling interval of $<1 \mathrm{~cm}$ or possibly $2 \mathrm{~cm}$, primarily because of the diameter of the transducer faces (approximately $2.5 \mathrm{~cm}$ ). The logging program used on Leg 108 averaged 250 readings, which gives a velocity approximately every $2 \mathrm{~cm}$ (i.e., about 75 readings for a $1.5-\mathrm{m}$ section). Figure 4 illustrates the type of data that can be obtained using a sampling interval of $2 \mathrm{~mm}$ (not significantly different on this scale to a sampling interval of $2 \mathrm{~cm}$ ) and compares it with a random selection of data points taken at $1.5-\mathrm{m}$ intervals that may have been typical had the Hamilton Frame been used.

\section{Repeatability and Axis Sensitivity}

It should be noted that the compressional wave pulse originates from an essentially linear contact between a flat transducer face and a cylindrical liner. The pulse travels across the diameter of the core and is, therefore, essentially measuring the velocity of the sediment within a relatively confined strip. The velocity obtained is not necessarily representative of the averaged sediment interval being measured within the cylindrical core. In practice, however, one can expect that the differences obtained by rotating the core will be negligible. A few experiments showed that only subtle differences occur as the core is rotated. 


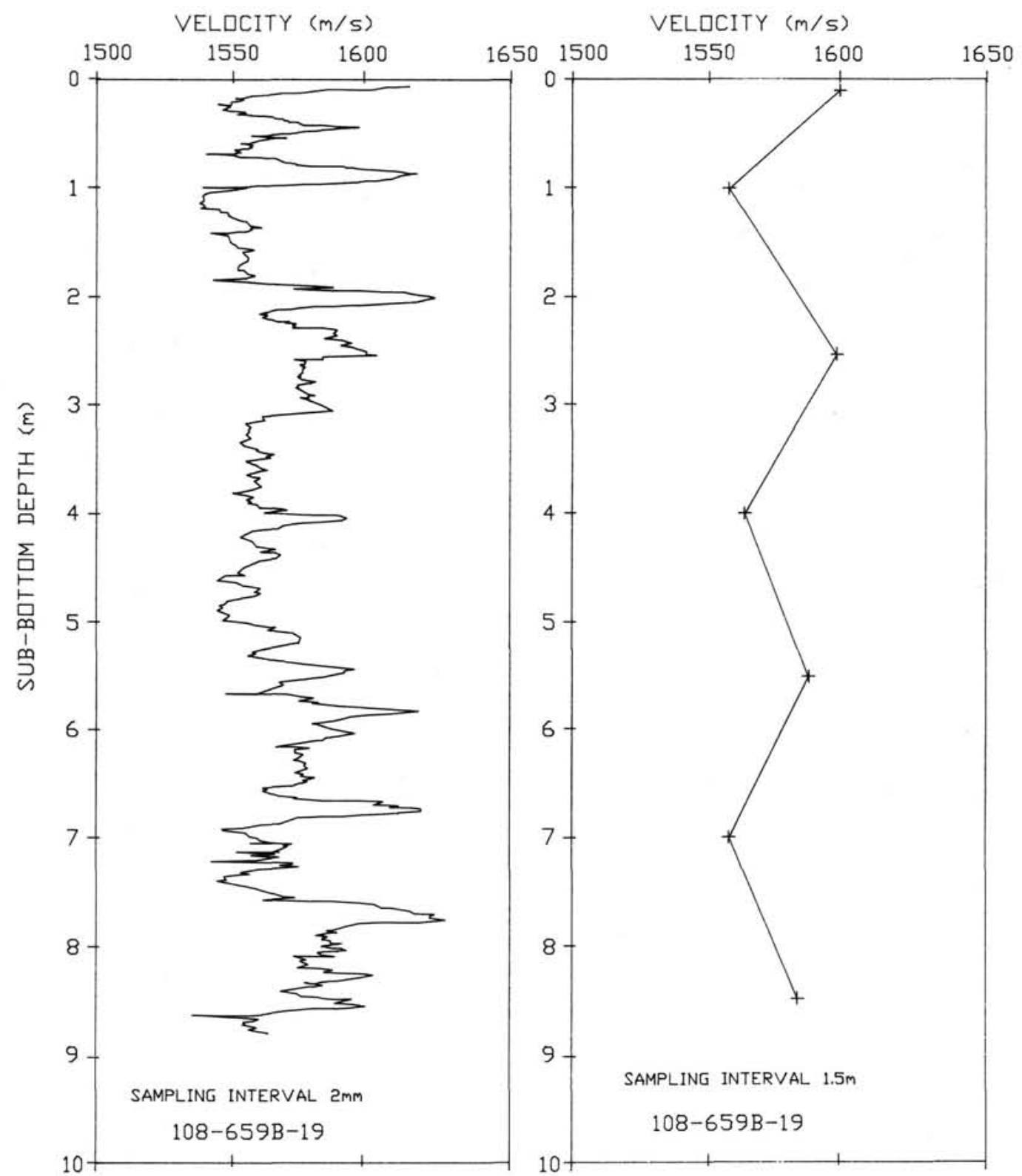

Figure 4. PWL profile for Core 108-659B-19H (left) compared with an example profile with $1.5-\mathrm{m}$ sampling intervals (right).

Figure 5 shows the logs for a complete core (108-664A-1H) taken at $45^{\circ}$-rotation intervals. One can see that some of the low-amplitude, high-frequency components change as the core is rotated. This is attributed to "physical noise" within the sediments (i.e., lateral physical heterogeneities within the sediments with wavelengths of less than a core diameter). This may be caused by bioturbation, coring disturbance, or a variety of other causes.

\section{SUMMARY AND CONCLUSIONS}

An automated system for rapidly and accurately measuring the compressional wave velocity profile in sediment cores has been developed. Velocity measurements are automatically taken at small intervals along each core section with the PWL, which is designed for incorporation into a whole-core logging system that could also include gamma- ray attenuation and magnetic susceptibility measurements. For evaluation purposes the PWL was used on Leg 108 alongside the GRAPE system. Over $3 \mathrm{~km}$ of cores were logged without any major difficulties, revealing fine-scale velocity structure in numerous cores that previously would not have been revealed.

Among the many applications possible for the technique are more accurate correlations with adjacent HPC holes, the generation of accurate synthetic seismograms, and the discovery of the nature of sedimentary features that are not easily or rapidly detected by conventional means.

\section{ACKNOWLEDGMENTS}

The authors wish to thank Rob Kidd and Elliott Taylor for their help in enabling the project to get off the ground and to Roger Flood and another unknown referee for some helpful comments on the draft manuscript. 


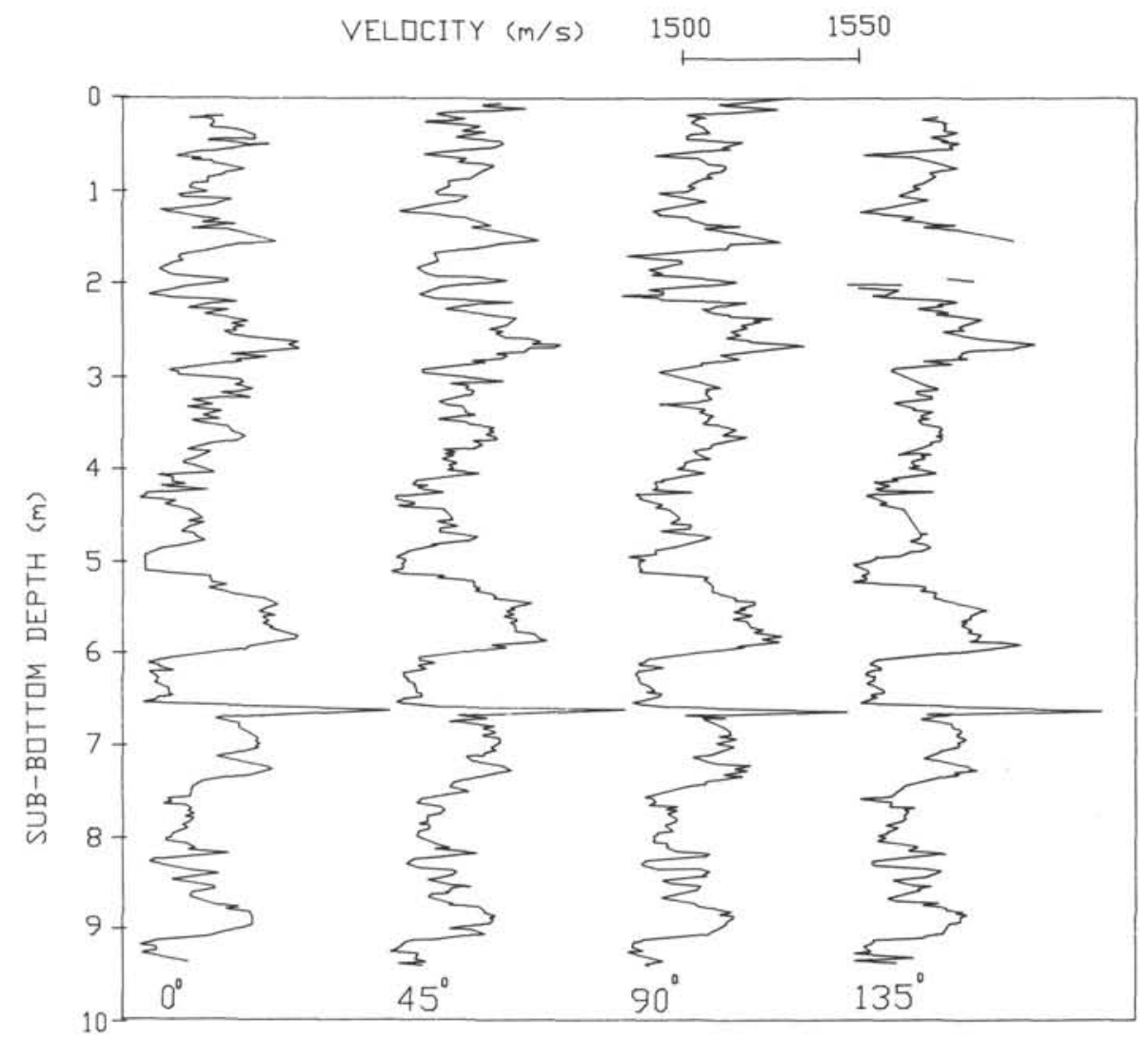

Figure 5. PWL profile for Core 108-664A-1H (sampled every $2 \mathrm{~cm}$ ) taken at $45^{\circ}$ rotation intervals across the axis.

\section{REFERENCES}

Boyce, R. E., 1973. Appendix I: Physical properties-methods. In Edgar, N. T., Saunders, J. B., et al., Init. Repts. DSDP, 15: Washington (U.S. Govt. Printing Office), 1115-1128.

1976. Appendix I: definitions and laboratory techniques of compressional sound velocity parameters and wet-water content, wet-bulk density, and porosity parameters by gravimetric and gamma ray attenuation techniques. In Schlanger, S. O., Jackson, E. D., et al., Init. Repts. DSDP, 33: Washington (U.S. Govt. Printing Office), 931-958.
Schultheiss, P. J., Meinert, J., and Shipboard Scientific Party, 1988. Whole-core $P$-wave velocity and gamma ray attenuation logs from Leg 108 (Sites 657 through 668). In Ruddiman, W., Sarnthein, M., et al., Proc. ODP, Init. Repts., 108, Sect. 2: College Station, TX (Ocean Drilling Program), 1015-1046.

Date of initial receipt: 8 March 1988

Date of acceptance: 13 January 1989 Ms 108B-157 